\title{
Cervical Spine Epidural Abscess Caused by Brucellosis: A Case Report and Literature Review
}

\author{
Misagh Shafizad ${ }^{1}$, Saeid Ehteshami ${ }^{1}$, Hamidreza Shojaei ${ }^{1}$, and Reza Jalili Khoshnoud ${ }^{2}$ \\ ${ }^{1}$ Mazandaran University of Medical Sciences \\ ${ }^{2}$ Shohada-e Tajrish Hospital
}

October 26, 2021

\begin{abstract}
We report a rare case of cervical epidural abscess at the C5-C6 levels. The patient underwent surgery with complete abscess removal through C6 vertebral body corpectomy. The result of bacteriological culture was Brucella melitensis. Brucellosis must be considered as a possible cause of epidural abscess in patients from endemic area.
\end{abstract}

\section{Hosted file}

Manuscript.docx available at https://authorea.com/users/442986/articles/543082-cervicalspine-epidural-abscess-caused-by-brucellosis-a-case-report-and-literature-review 


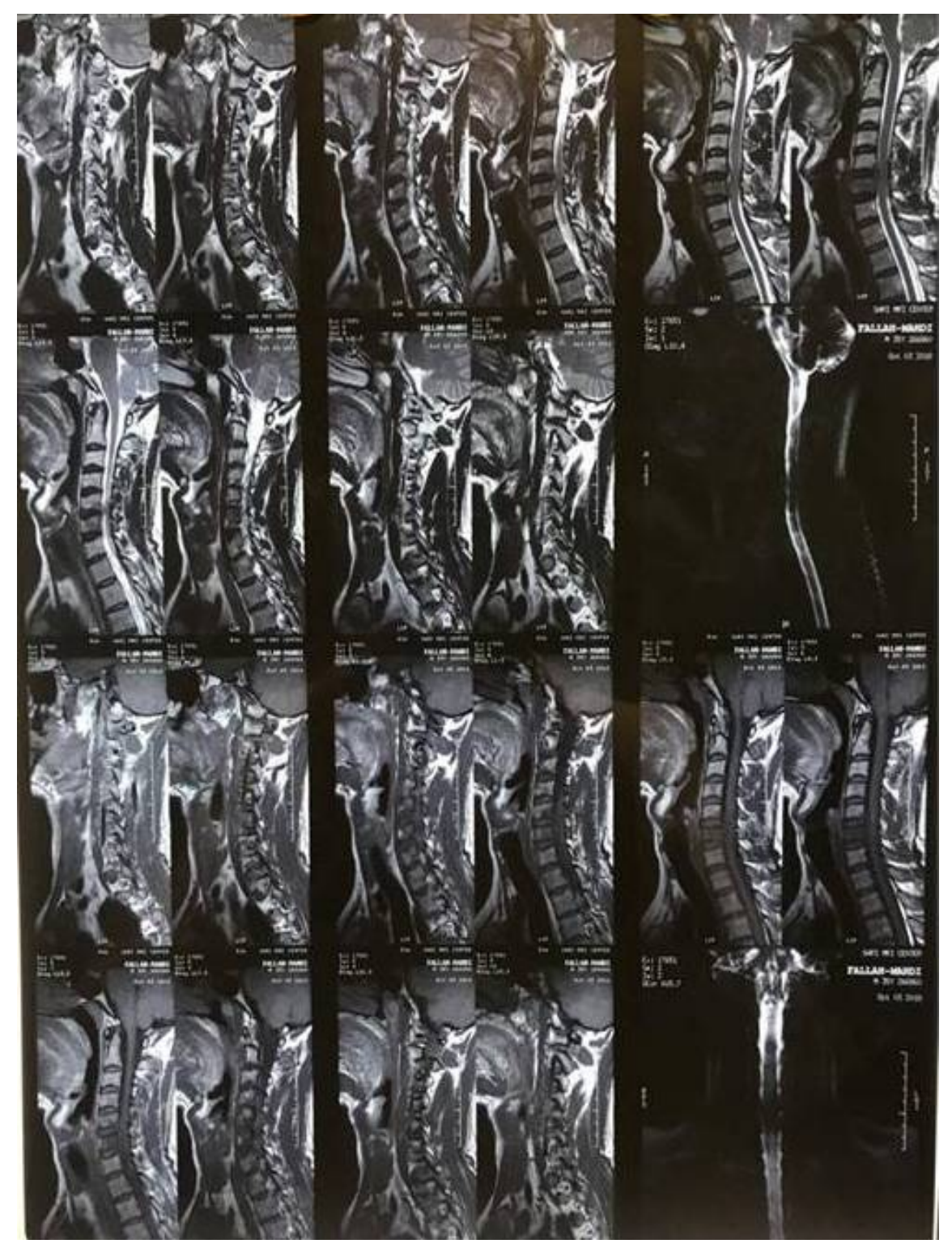




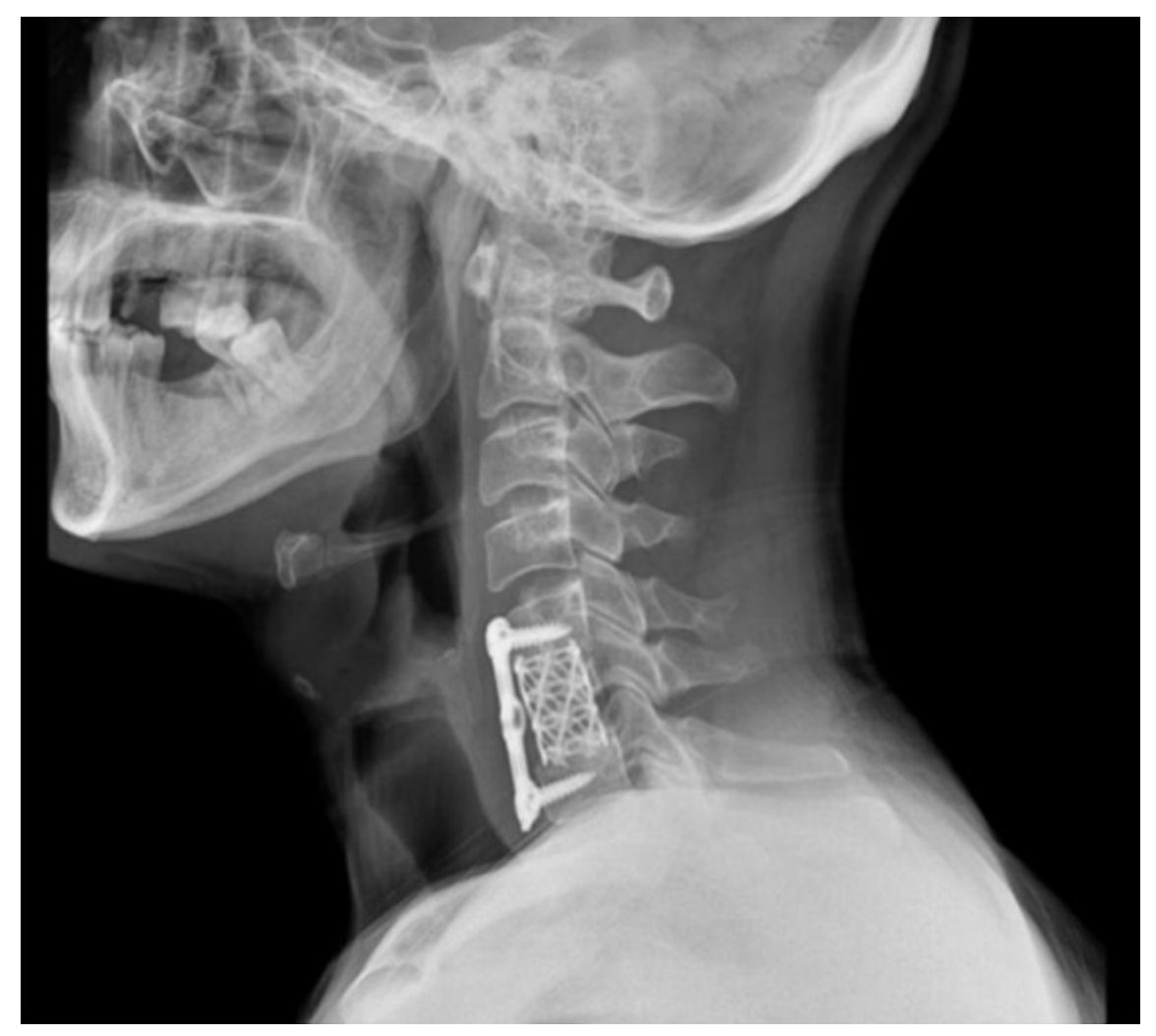

